\title{
AUTOMATIC DETECTION AND RECOGNITION OF CRATERS BASED ON THE SPECTRAL FEATURES OF LUNAR ROCKS AND MINERALS
}

\author{
L. Ye ${ }^{\text {a }}$, X. Xu ${ }^{\text {a }}$, D. Luan ${ }^{\text {a }}$ W. Jiang ${ }^{\text {a }}$, Z. Kang ${ }^{\text {a } *}$ \\ a Surveying and Mapping Engineering, School of Land Science and Technology, China University of Geosciences \\ (Beijing), Xueyuan Road, Haidian District, Beijing, 100083 CN - ljyebj@163.com
}

KEY WORDS: Spectral Characteristics, MI , Band Ratio Method, Impact Crater Classification

\begin{abstract}
:
Crater-detection approaches can be divided into four categories: manual recognition, shape-profile fitting algorithms, machine-learning methods and geological information-based analysis using terrain and spectral data. The mainstream method is Shape-profile fitting algorithms. Many scholars throughout the world use the illumination gradient information to fit standard circles by least square method. Although this method has achieved good results, it is difficult to identify the craters with poor "visibility", complex structure and composition. Moreover, the accuracy of recognition is difficult to be improved due to the multiple solutions and noise interference. Aiming at the problem, we propose a method for the automatic extraction of impact craters based on spectral characteristics of the moon rocks and minerals: 1) Under the condition of sunlight, the impact craters are extracted from MI by condition matching and the positions as well as diameters of the craters are obtained. 2) Regolith is spilled while lunar is impacted and one of the elements of lunar regolith is iron. Therefore, incorrectly extracted impact craters can be removed by judging whether the crater contains "non iron" element. 3) Craters which are extracted correctly, are divided into two types: simple type and complex type according to their diameters. 4) Get the information of titanium and match the titanium distribution of the complex craters with normal distribution curve, then calculate the goodness of fit and set the threshold. The complex craters can be divided into two types: normal distribution curve type of titanium and non normal distribution curve type of titanium. We validated our proposed method with MI acquired by SELENE. Experimental results demonstrate that the proposed method has good performance in the test area.
\end{abstract}

\section{INTRODUCTION}

The Moon is the nearest celestial body to the Earth and catches lots of attention for a long time(Ouyang, 2005). The surface of lunar is covered with a variety of big and small circular structures including craters, lunar rays and arched structures associated with craters, which are significant features of the lunar surface (Ouyang, 2005). The formation process of impact craters, morphological characteristics and spatial distribution provide clues and methods of the study about the lunar evolution in different aspects for people (Huang, 2009). The researches on lunar craters have a significant influence on the process of human understanding and exploration of the moon.

At present, the researches on impact craters in the world mainly attach importance to how to extract impact craters in CCD images or DEM data by using related algorithms. Few scholars have carried out further research on the extracted craters. Based on the illumination gradient information, Junhua Feng et al use the Chang'e-1 CCD images to fit the edge ellipses by the least square method (Feng, 2010). Zongyu Yue et al studied on the identification of impact craters using the visible / near-ultraviolet band images obtained from Clementine (Yue, 2008). Based on cross-correlation, M Magee et al proposed a method of template matching, which is calculated by the standardized crosscorrelation method and found that the method is suitable for small, relatively simple craters (Magee, 2003). Y Sawabe et al added UV-VIS band multispectral data to the study about the automatic identification and classification of craters from Clenmentine and Apollo lunar highlands and lunar mare. In the experiment, they found that the $\mathrm{FeO} 2$ content in the crater was lower than that in the surrounding area (Sawabe, 2005). Based on the Hough transformation, K Homma introduces the thought of parallel computing, experimenting with SELENE image data, increasing the computational speed greatly without affecting the recognition accuracy (K Homma, 1997). Jr Kim et al eliminated more than $85 \%$ error extracted carters by using the Eigenspace construction algorithm based on artificial neural networks proposed by Turk and Pentland (Kim, 2005). Tomasz F Stepinski, Erik R Urbach et al used the decision tree algorithm for the candidate impact craters, which is based on setting decision conditions to determine whether they belong to impact craters. (Stapinski,2009; Urbach,2009).

Taking into account the accuracy of the data constraints, impact craters have a high error extraction rate. Few scholars try to remove error craters and automatically classify them. Accordingly, we propose an algorithm to determine the correctness of the extracted craters and realize the automatic classification based on the spectral characteristics of the lunar rock and minerals in this paper.

\section{EXTRACT CRATERS FROM MI}

Under the conditions of sunlight, Zhongfei Luo used CCD data whose spectral channel is $500-700 \mathrm{~nm}$ (Chen, 2009) to extract the craters by an automatic detection algorithm based on feature matching (Luo, 2014). The thinking of extraction includes threshold segmentation, region growing, adding conditions of image characters, extracting the edge of craters and fitting into standard circles. The extraction is based on four image characters. Figure 1 is the flow diagram of extracting algorithm.

\footnotetext{
* Corresponding author. This is useful to know for communication with the appropriate person in cases with more than one author.
} 


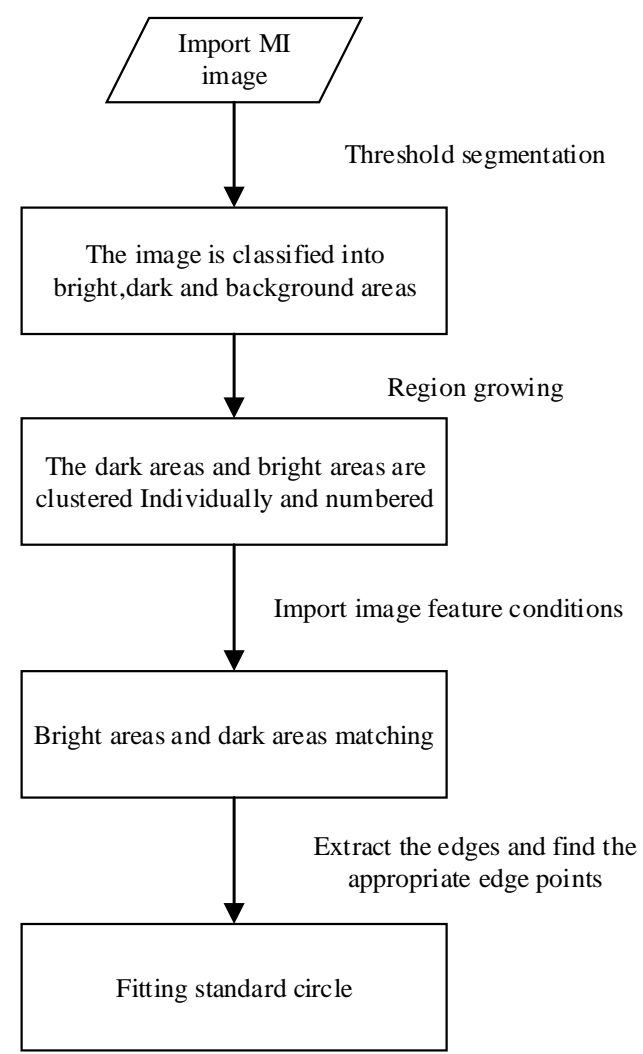

Figure 1. Automatic crater detection algorithm based on feature matching

MI data contains 9 bands and the Spectral channel is 415$1550 \mathrm{~nm}$. Because craters in MI images still match the four image characters: (1)The edges of craters are close to circle. (2) The line which connects the center of the highlight and the shadow is nearly parallel to the direction of sun light. (3)The ratio between the area of the craters and distance between the center of light and the shadow fluctuates in a certain range. (4)The gray value variation of the light and the shadow is small (Jin, 2009), we can use the algorithm proposed by Luo to extract the craters. We use the matching features, as follows to extract craters.

$$
\begin{array}{lr}
\theta<20^{\circ} & \\
s=\left(S_{a}+S_{b}\right) / \pi r^{2} & s>0.3 \\
p=\min \left(S_{a} / S_{b}, S_{b} / S_{a}\right) & p<3.9
\end{array}
$$

where $\theta=$ the angle between direction of sun light and line connecting the center of the highlight and the shadow. $S=$ the ratio between number of pixels in the light and shadow and area of a circle whose radius equals the distance between the center of light and shadow. $S_{a}=$ the number of pixels in the shadow.

$S_{b}=$ the number of pixels in the light.

$r=$ the distance between the center of light and shadow.

$p=$ the minimum value of the ratio between the number of pixels in the shadow and the light.

Figure 2 is the effect picture of extracting craters in a sample of MI images.

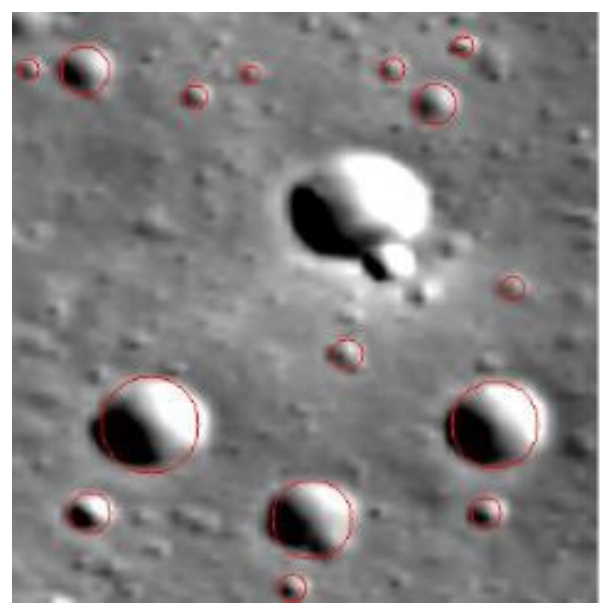

Figure 2. Effect picture of extraction algorithm based on feature matching $\left(\mathrm{N} 39^{\circ}-40^{\circ}, \mathrm{E} 323^{\circ}-324^{\circ}\right.$, the center wavelength is $1548 \mathrm{~nm}$, the spatial resolution is $62 \mathrm{~m}$ )

\section{ERROR ELIMINATION}

The structure and material composition of the impact craters is complicated, and the lighting conditions vary from region to region. It leads to that provided that merely in the sunlight, the extractions of the impact craters on CCD images which based on condition matching have error extractions. In this paper, by determining whether the standard circles contain "non iron" element, we make error eliminations for the craters which have been extracted by the extraction algorithm based on feature matching. Due to the special environment of the lunar, lunar regolith has unique mineral composition and completely different from the earth, and there is a great quantity of nanoscale elemental iron in the lunar regolith particles even cemented glass because of a lot of space weathering (Taylor LA., 2005). The mineral absorption characteristics of the moon are mainly influenced by ferrous iron and titanium from the crystal structure aspect (Wang Zhenchao, 2011). In the study of data from Clenmentine and Apollo lunar highlands and lunar mare, Y Sawabe et al found that the concentration of $\mathrm{FeO} 2$ in the crater was much lower than in the surrounding area (Sawabe, 2005).

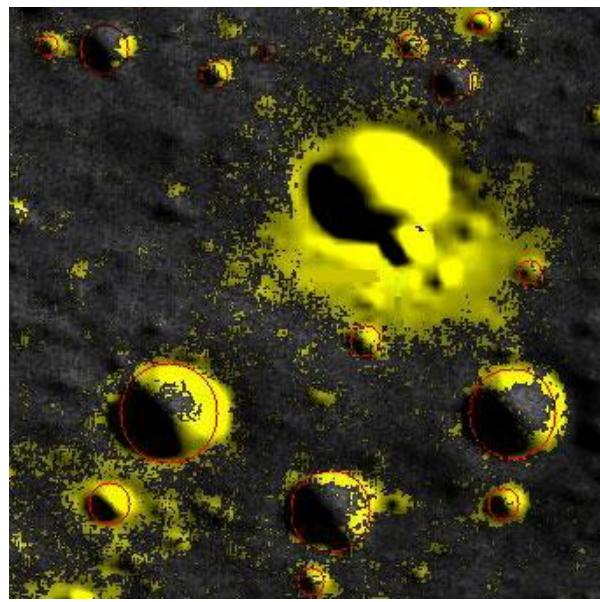

Figure 3. Effect picture of error elimination (N39 ${ }^{\circ}-40^{\circ}$, E323 ${ }^{\circ}$ $324^{\circ}$, the center wavelength is $1548 \mathrm{~nm}$, the spatial resolution is $62 \mathrm{~m}$, the yellow area in the picture is defined as regions rich in "non iron" element, and the gray area are regions rich in iron)

Lunar regolith contains a large amount of iron. It can be inferred that when a meteorite strikes the moon, the lunar regolith was spilled, the iron content in the craters less compared to the 
outside. The iron information can be extracted using the central wavelength of $1250 \mathrm{~nm} / 750 \mathrm{~nm}$ (Yu, 2009). We make iron extraction ratio less than a certain threshold defined as "non iron" element. If the extracted standard circle contains the "non iron" element, it can be considered that the standard circle is extracted correctly, otherwise it is wrong. Figure 3 is the effect picture of error elimination.

\section{CRATER CLASSIFICATION}

In this paper, we divided the correct craters into the simple and complex type, and the complex type can be divided into normal distribution curve type of titanium and non normal distribution curve type of titanium.

\subsection{Divide Craters into Simple and Complex Type}

The air of the moon is very thin and it almost can be considered a vacuum. Its surface crystalline rock, molten glass etc directly exposed to the universe, suffered from the solar wind, cosmic rays and meteorites radiation and impact. The surface of the depth of about tens of nanometers formed because of weathering influences (Wang, 2011). The impact strength and weathering effect of large-diameter impact craters are generally stronger relative to small-diameter craters, and their morphological and material composition is more complex. The diameter of simple crater is generally less than $4 \mathrm{~km}$ (Zhao, 2011).

Table 1 is for the sample area of the four craters whose diameters are about $4 \mathrm{~km}$. It can be seen that the profile line and the distribution of titanium content in the craters are quite different. Therefore, we use $4 \mathrm{~km}$ as the threshold, the diameter of crater less than $4 \mathrm{~km}$ is divided into simple impact crater, more than $4 \mathrm{~km}$ is divided into complex crater.

\subsection{The Classification of Complex Craters}

Mare basalt can be divided into three types based on the content of titanium, namely high titanium basalt, low titanium basalt, and high-alumina low-titanium basalt (Cloutis, 1991). As shown in Table 2, the shape of the more regular crater such as flat, no uplift, etc., the titanium content distribution curve in line with or similar to the normal distribution. Irregular shape of the impact of the crater, such as containing the central peak and uplift, etc., the titanium content distribution curve in the fitting of the normal curve effect is much worse. We can determine the result of fitting by calculating the adjusted R-square of fit. The formula is as equation (2).

$$
\text { adjusted } R \text { - square }=1-S S E(n-1) / S S T(v)
$$

Where

$$
\begin{aligned}
& S S E=\sum_{i=1}^{n} w_{i}\left(y_{i}-\hat{y}_{i}\right)^{2} \\
& S S T=\sum_{i=1}^{n} w_{i}\left(y_{i}-\bar{y}\right)^{2}
\end{aligned}
$$

The information of the titanium element is extracted by the band ratio with the center wavelength of $415 \mathrm{~nm} / 750 \mathrm{~nm}$ (Yu, 2009). The non normal distribution curve type of titanium craters should match following formula:

$$
\text { adjusted } R-\text { square }=1-\operatorname{SSE}(n-1) / \operatorname{SST}(v)<=0.9
$$

Otherwise the craters are classified as normal distribution curve type of titanium.

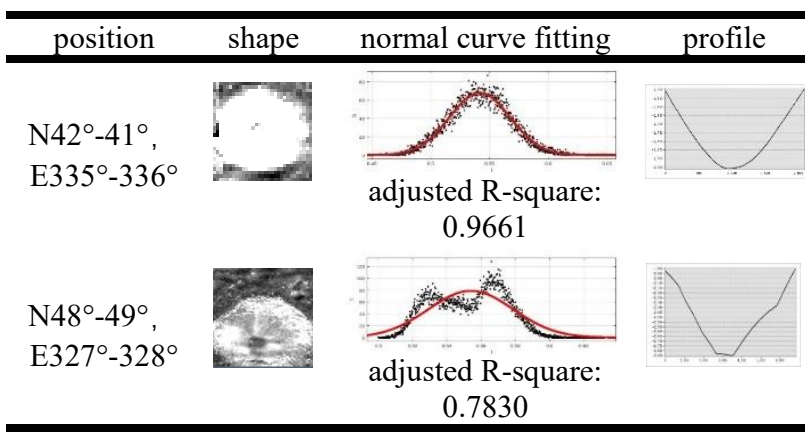

Table 2. A comparison of regular and irregular craters

\section{EXPERIMENT AND ANALYSIS}

The method described in this paper based on the data of multi band images (MI) obtained by SELENE. The total number of bands is nine. Wavelengths of five bands located in visible light spectrum are $415 \mathrm{~nm}, 750 \mathrm{~nm}, 900 \mathrm{~nm}, 950 \mathrm{~nm}, 1000 \mathrm{~nm}$. Those images have $20 \mathrm{~m}$ spatial resolution. Another four bands whose spatial resolution is $62 \mathrm{~m}$ belong to near-infrared and their wavelengths are $1000 \mathrm{~nm}, 1050 \mathrm{~nm}, 1250 \mathrm{~nm}, 1548 \mathrm{~nm}$. We use DEM from LOLA of LRO, whose spatial resolution is $30 \mathrm{~m}$,

\begin{tabular}{|c|c|c|c|c|c|c|}
\hline number & position & shape & diameter & normal curve fitting & adjusted R-square & profile \\
\hline 1 & $\mathrm{~N} 41^{\circ}-40^{\circ}, \mathrm{E} 334^{\circ}-335^{\circ}$ & & $4.0 \mathrm{~km}$ & & 0.9200 & \\
\hline 2 & $\mathrm{~N} 41^{\circ}-40^{\circ}, \mathrm{E} 335^{\circ}-336^{\circ}$ & & $4.4 \mathrm{~km}$ & & 0.8662 & \\
\hline 3 & $\mathrm{~N} 42^{\circ}-41^{\circ}, \mathrm{E} 335^{\circ}-336^{\circ}$ & & $4.5 \mathrm{~km}$ & & 0.9661 & \\
\hline 4 & $\mathrm{~N} 43^{\circ}-42^{\circ}, \mathrm{E} 329^{\circ}-330^{\circ}$ & & $4.2 \mathrm{~km}$ & & 0.8744 & \\
\hline
\end{tabular}
comparing with results of our method to judge the accuracy of our classification. The tested area located in a mid-latitude area from $39^{\circ} \mathrm{N}-50^{\circ} \mathrm{N}, 25^{\circ} \mathrm{W}-38^{\circ} \mathrm{W}$ in Sinus Iridum.

Table 1. A comparison of 4 impact craters whose diameters are about $4 \mathrm{~km}$.

\subsection{Result of Extraction in MI}

Carry out threshold segmentation, region growing, adding conditions of image characters, extracting the edge of craters and fitting into standard circles to the MI image of $\mathrm{N} 39^{\circ}-40^{\circ}, \mathrm{E} 323^{\circ}-$ $324^{\circ}$. Figure 4 shows the result of extraction. 


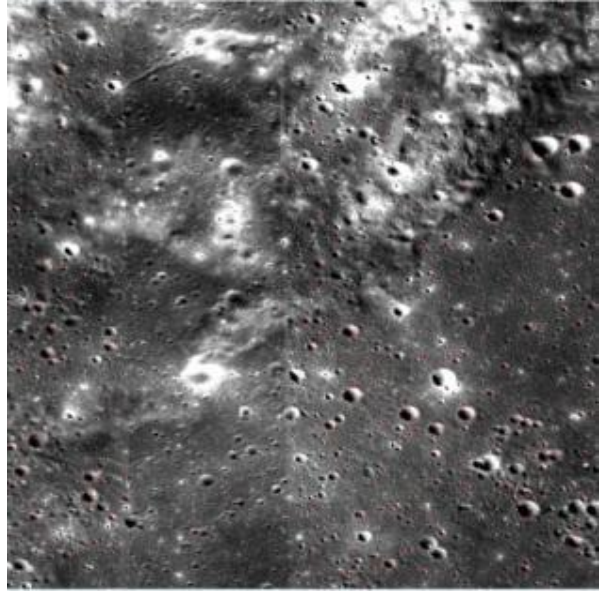

Figure 4. The result of extraction. The strip in the picture was obtained under different sunlight condition. As a result, some craters were not extracted in this paper. We just discuss wrong extraction. We do not take non extracted into consideration.

\subsection{Elimination of Wrong Extracted Craters}

We deal with the above image by using band ratio $1250 \mathrm{~nm} / 750 \mathrm{~nm}$ to get the information of iron. After processing, the max and min of DN value in this image are 2.522866 and 0.997822 separately. Then, set the area whose $\mathrm{DN}$ value between 0.997822 and 1.35 as "non iron" area. The testing result was in Figure 5. Craters in red circles are extracted by the algorithm based on feature matching. In the red squares are craters right for artificial recognition but wrong for "non iron" algorithm. Pink squares show craters wrong for artificial recognition, right for "non iron" algorithm. Green squares are right for both artificial recognition and "non iron" algorithm. Other craters signed only by red circles are wrong for both artificial recognition and "non iron" algorithm.

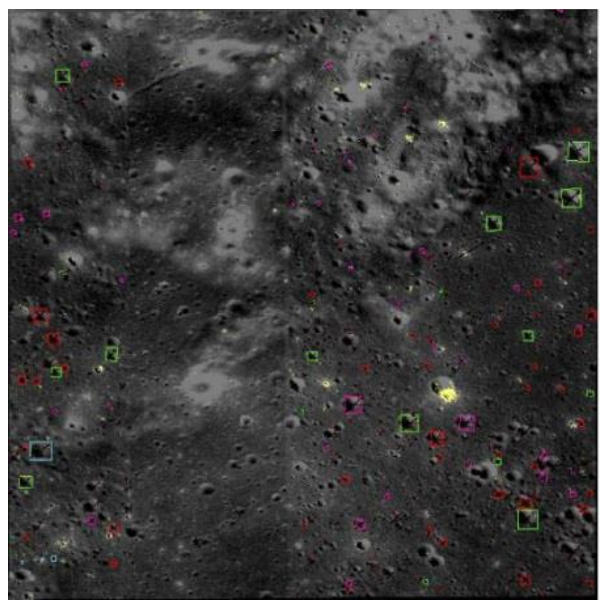

Figure 5. Extracting and "non iron" algorithm result

By judging whether the extracted standard circle contains "non iron" region or not, the correctness of the impact crater could be judged. Table 3 is the confusion matrix of 505 extracted craters.

\begin{tabular}{ccc}
\hline Artificial Recognition & right & wrong \\
\hline "Non iron" Algorithm & & \\
\hline right & 20 & 36 \\
wrong & 65 & 384 \\
\hline
\end{tabular}

Table 3. Confusion matrix of wrong extracted craters
Accuracy of algorithm based on feature matching:

$(20+65) \quad / 505=16.8 \%$

Accuracy of "non iron" algorithm:

$(20+384) \quad / 505=80.0 \%$

As is shown above, in mid-latitude area the accuracy of algorithm based on feature matching is low. What is more, after adding "non iron" algorithm, the accuracy significantly improved.

\subsection{Identify the Types of Craters}

There are no craters whose diameters are greater than $4 \mathrm{~km}$ in $\mathrm{N} 39^{\circ}-40^{\circ}, \mathrm{E} 323^{\circ}-324^{\circ}$, so all the craters in this area belong to simple type. Gather statistics of craters whose diameters are greater than $4 \mathrm{~km}$ in $\mathrm{N} 40^{\circ}-50^{\circ}, \mathrm{E} 322^{\circ}-335^{\circ}$. Carry out band ratio $415 \mathrm{~nm} / 750 \mathrm{~nm}$ to these images, to get the information of titanium (Yu, 2009). Match the distribution of titanium with normal distribution curve and calculate the adjusted R-square. In the following table 4 , craters $1,3,5,7,8,9,10,11,13$ have adjusted $\mathrm{R}$-square less than 0.9 , they are non normal distribution curve type of titanium, others are normal distribution curve type of titanium.

\subsection{Discussion}

Currently, the research on impact craters in the world mainly stays at the extraction level, and the accuracy of the extraction is limited due to the limitation of the data accuracy and the multiplicity of Solutions. What's more, few scholars study further inspection and classification after extracting the craters. Aiming at this problem, this paper presents a crater inspection and classification algorithm based on the spectral characteristics of lunar rocks and minerals.

In the process of experiment, we found that the distribution of iron in the crater is less, while iron is rich in lunar regolith. Therefore, speculated that this phenomenon is due to the impact on surface, soil is splashing out. Based on the statistics of 15 craters with diameter greater than or equal to $4 \mathrm{~km}$ in the experimental area, it is found that the diameter of the crater approximately $4 \mathrm{~km}$ shows great difference. Hence, in this article, threshold as the $4 \mathrm{~km}$ in diameter, craters whose diameters are less than $4 \mathrm{~km}$ are divided into simple type, the others are divided into complex type. Some craters whose wall or bottom has uplifted part, and the distribution of titanium content have a large proportion near the uplifted part, as shown in Figure 6.

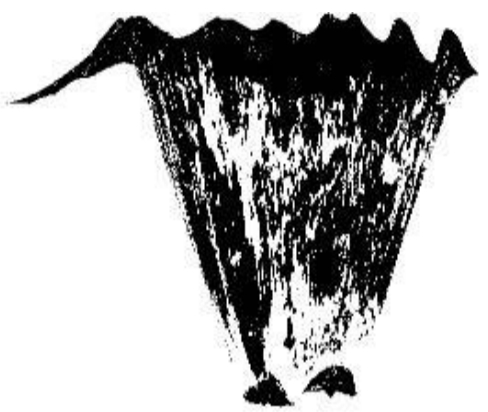

Figure 6. Effect picture of titanium content in impact crater, the white area is relatively high content of titanium parts, $\mathrm{N} 43^{\circ}-44^{\circ}, \mathrm{E} 333^{\circ}-334^{\circ}$

Speculates that is because the craters breaking the surface material, release of pressure results to the spring back and the deeper underground materials exposed. Speculates that the 
mechanism is shown in Figure 7.

\begin{tabular}{|c|c|c|c|c|c|c|c|c|}
\hline $\begin{array}{l}\text { numbe } \\
r\end{array}$ & position & shape & diameter & Type & $\begin{array}{c}\text { normal } \\
\text { fitting }\end{array}$ & curve & $\begin{array}{l}\text { adjusted R- } \\
\text { square }\end{array}$ & profile \\
\hline 1 & $\begin{array}{c}\mathrm{N} 41^{\circ}-40^{\circ} \\
\text { E323응 }-324^{\circ}\end{array}$ & & $7.6 \mathrm{KM}$ & Non normal & & & 0.8949 & \\
\hline 2 & $\begin{array}{c}\mathrm{N} 41^{\circ}-40^{\circ} \\
\text { E334 }\end{array}$ & & $4 \mathrm{KM}$ & Normal & & & 0.92 & \\
\hline 3 & $\begin{array}{l}\mathrm{N} 41^{\circ}-40^{\circ} \\
\text { E335 }\end{array}$ & & $4.4 \mathrm{KM}$ & Non normal & & & 0.8662 & \\
\hline 4 & $\begin{array}{l}\mathrm{N} 42^{\circ}-41^{\circ} \\
\mathrm{E} 335^{\circ}-336^{\circ}\end{array}$ & & $4.5 \mathrm{KM}$ & Normal & & & 0.9661 & \\
\hline 5 & $\begin{array}{l}\mathrm{N} 43^{\circ}-42^{\circ} \\
\mathrm{E} 329^{\circ}-330^{\circ}\end{array}$ & & $4.2 \mathrm{KM}$ & Non normal & & & 0.8744 & \\
\hline 6 & $\begin{array}{l}\mathrm{N} 44^{\circ}-43^{\circ} \\
\mathrm{E} 326^{\circ}-327^{\circ}\end{array}$ & & $5.2 \mathrm{KM}$ & Normal & & & 0.9142 & \\
\hline 7 & $\begin{array}{c}\mathrm{N} 44^{\circ}-43^{\circ} \\
\text { E333응 }\end{array}$ & & $14 \mathrm{KM}$ & Non normal & & & 0.7835 & \\
\hline 8 & $\begin{array}{c}\mathrm{N} 44^{\circ}-43^{\circ} \\
\mathrm{E} 335^{\circ}-336^{\circ}\end{array}$ & & $4 \mathrm{KM}$ & Non normal & & & 0.7927 & \\
\hline 9 & $\begin{array}{c}\mathrm{N} 46^{\circ}-45^{\circ} \\
\mathrm{E} 325^{\circ}-326^{\circ}\end{array}$ & & $5.2 \mathrm{KM}$ & Non normal & & & 0.8298 & \\
\hline 10 & $\begin{array}{c}\mathrm{N} 47^{\circ}-46^{\circ} \\
\text { E } 327^{\circ}-328^{\circ}\end{array}$ & & $7 \mathrm{KM}$ & Normal & & & 0.8463 & \\
\hline 11 & $\begin{array}{c}\mathrm{N} 48^{\circ}-47^{\circ} \\
\text { E323잉 }\end{array}$ & & $7.4 \mathrm{KM}$ & Non normal & & & 0.8959 & \\
\hline 12 & $\begin{array}{l}N 49^{\circ}-48^{\circ} \\
\text { E326 }\end{array}$ & & $15 \mathrm{KM}$ & Normal & & & 0.9292 & \\
\hline 13 & $\begin{array}{c}\mathrm{N} 49^{\circ}-48^{\circ} \\
\mathrm{E} 327^{\circ}-328^{\circ}\end{array}$ & & $12 \mathrm{KM}$ & Non normal & & & 0.783 & \\
\hline 14 & $\begin{array}{c}N 49^{\circ}-48^{\circ} \\
\text { E328 }\end{array}$ & & $8 \mathrm{KM}$ & Normal & & & 0.9393 & \\
\hline 15 & $\begin{array}{c}N 50^{\circ}-49^{\circ} \\
\text { E } 334^{\circ}-335^{\circ}\end{array}$ & & $10 \mathrm{KM}$ & Normal & & & 0.9455 & \\
\hline
\end{tabular}

Table 4. Statistical table of impact craters whose diameters are greater than $4 \mathrm{~km}$

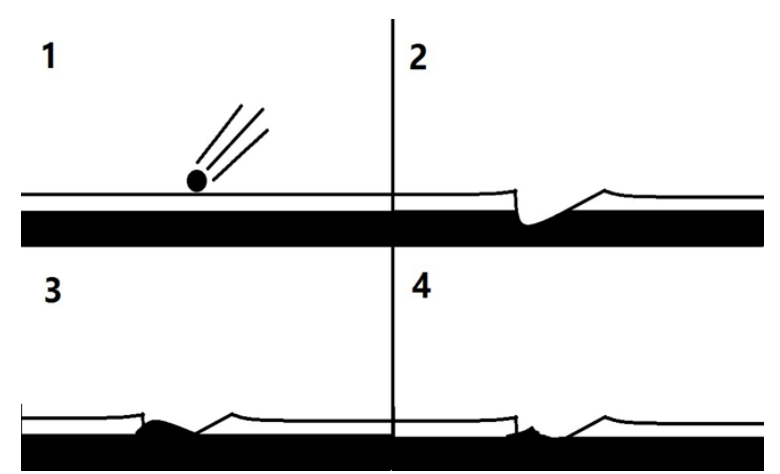

Figure 7. Schematic diagram of the different forming mechanism of the uplift part and the non-uplift part of the titanium content. The white and black parts in the figure are different strata, and their titanium content is different.

It is believed that with the improvement of data accuracy and the optimization of research methods, the relative relationship between the material composition and its morphological structure will be deeper understood and investigated.

\section{CONCLUSIONS}

Based on the spectral characteristics of the lunar rocks and minerals, the error removal and the classification of impact craters are carried out in this paper, and the following conclusions are obtained:

1. By determining whether the standard circle contains "non iron" element to determine whether the extraction of the craters is correct, we raised the crater correct extraction rate from $16.8 \%$ to $80.0 \%$ in the mid-latitude test area.

2. We calculated 15 craters whose diameters are greater than $4 \mathrm{~km}$ in the test area. The titanium content distribution of each complex crater was compared with normal curve. After the threshold was set by adjusted R-square, we 
divided the complex craters into the normal/non normal distribution curve type of titanium, in order to achieve the purpose of classification of complex craters.

3. A classification of complex types based on the distribution of titanium content is proposed.

Due to the limited number of impact craters in the test area and the complexity of the morphological structure and material composition of the impact crater itself, the method we proposed has large room for improvement. We will study the relative relationship between the morphological structure and the material composition in the next stage and try to use the method of deep learning in which a large number of craters will be trained to improve the accuracy of the algorithm and be fully automated.

\section{REFERENCE:}

Chen, W., 2009. The identification of special targets based on special features of Chang'e-1 CCD data. Remote Sensing for Land \& Resources, (4), pp. 40-44.

Feng, J., 2010. Autonomous crater detection and matching on planetary surface. Acta Aeronautica et Astronautica Sinica, 31(9), pp. 1858-1863.

Homma, K., 1997. Massively parallel processing for crater recognition. Lunar and Planetary Science XXVIII, pp. 589.

Jin, L., 2009. Characteristics of lunar craters on the first image of Chang'e-1 satellite. Journal of Jilin University (Earth Science Edition), 39(5), pp. 942-946.

Kim, J., 2005. Automated crater detection, a new tool for mars cartography and chronology. Photogrammetric Engineering \& Remote Sensing, 71(10), pp. 1205-1217.

Luo, Z., 2014. The automatic extraction and recognition of lunar impact craters fusing CCD images and DEM data of Chang'e-1. Acta Geodaetica et Gartographica Sinica, 43(9), pp. 924-930.

Magee, M., 2003. Automated identification of Martian craters using image processing. Lunar and Planetary Science XXXIV, pp. 2-3.

Sawabe, Y., 2005. Automatic crater detection algorithm for the lunar surface using multiple approaches. Journal of Remote Sensing Society of Japan, 25(2), pp. 157-168.

Stepinski, T., 2009. Machine cataloging of impact craters on mars. Icarus, 203(1), pp. 77-87.

Turk, M., 1991. Eigenfaces for recognition. Journal of Cognitive Neuroscience, 3(1), pp. 71-86.

Urbach, E., 2009. Automatic detection of Sub-Km craters in high resolution planetary images. Planetary \& Space Science, 57(7), pp. 880-887.

Wang, J., 2015. A global inventory of lunar craters: identification, classification, and distribution. Progress in Geography, 34(3), pp. 330-339.

Wang, Z., 2011. Analysis of spectral charateristics of Lunar soil and quantitative inversion of minerals information. China University of Geosciences (Beijing).
Yu, Y., 2009. The inversion of vegetation structural parameters using dual-baseline polarimetric SAR interferometry. Remote Sensing for Land \& Resources, (4), pp. 45-52.

Yue, Z., 2008. Automatic identification by object-oriented classification method. Chinese Science Bulletin, 53(22), pp. 2809-2813. 